\title{
Cellular senescence: A pathogenic mechanism of pelvic organ prolapse (Review)
}

\author{
LIWEI HUANG $^{1,2^{*}}$, ZHIWEI ZHAO ${ }^{3 *}$, JIRUI WEN $^{3}$, WANG LING $^{1}$, YALI MIAO ${ }^{4}$ and JIANG WU ${ }^{1}$ \\ ${ }^{1}$ Deep Underground Space Medical Center, West China Hospital, \\ Sichuan University; ${ }^{2}$ West China School of Stomatology Medicine, Sichuan University; \\ ${ }^{3}$ West China School of Basic Medical Sciences and Forensic Medicine, Sichuan University; \\ ${ }^{4}$ Department of Obstetrics and Gynecology, Key Laboratory of Birth Defects and Related Diseases of Women and \\ Children of MOE, West China Second University Hospital, Sichuan University, Chengdu, Sichuan 610041, P.R. China
}

Received October 1, 2019; Accepted June 22, 2020

DOI: $10.3892 / \mathrm{mmr} .2020 .11339$

\begin{abstract}
Pelvic organ prolapse (POP) is a common symptom of pelvic floor disorders which is characterized by the descent of the uterus, bladder or bowel from their normal anatomical position towards or through the vagina. Among the older population, the incidence of POP increases with age. It is becoming necessary to recognize that POP is a degenerative disease that is correlated with age. In recent years, studies have been performed to improve understanding of the cellular and molecular mechanisms concerning senescent fibroblasts in pelvic tissues, which contribute to the loss of structure supporting the pelvic organs. These mechanisms can be classified into gene and mitochondrial dysfunctions, intrinsic senescence processes, protein imbalance and alterations in stem cells. The present review provides an integrated overview of the current research and concepts regarding POP, in addition to discussing how fibroblasts can be targeted to evade the negative impact of senescence on POP. However, it is probable that other mechanisms that can also cause POP exist during cell senescence, which necessitates further research and provides new directions in the development of novel medical treatment, stem cell therapy and non-surgical interventions for POP.
\end{abstract}

Correspondence to: Professor Jiang Wu, Deep Underground Space Medical Center, West China Hospital, Sichuan University, 37 Guoxuexiang Road, Chengdu, Sichuan 610041, P.R. China E-mail: jw@scu.edu.cn

Professor Yali Miao, Department of Obstetrics and Gynecology, Key Laboratory of Birth Defects and Related Diseases of Women and Children of MOE, West China Second University Hospital, Sichuan University, 17 Renmin Nanlu Road, Chengdu, Sichuan 610041, P.R. China

E-mail: miaoyali2006@163.com

*Contributed equally

Key words: pelvic organ prolapse, fibroblasts, aging, senescence, gene damage, epigenetic

\section{Contents}

1. Introduction

2. Increases in oxidative stress causes fibroblast cell damage in the pelvic tissue

3. Mitochondrial dysfunction in fibroblasts

4. General cellular phenotype associated with the pathogenesis of POP

5. Imbalanced proteostasis in fibroblasts of pelvic tissues

6. Obstacles and outlook

7. Conclusion

\section{Introduction}

Pelvic organ prolapse (POP) is a common symptom of pelvic floor disorders that is characterized by loss of support to the uterus, bladder and bowel, leading to their descent from their normal anatomic position towards or through the vagina (1). Pelvic floor disorders affect a substantial proportion of women in the USA, where the incidence increases with age (2). In total, $\geq 75 \%$ women receiving routine gynecological care exhibit some levels of prolapse (2). The risk of POP increases with age, reaching a peak in individuals aged 60-69 years (3). A sample study previously revealed that women in the 60-70 years age group experience higher levels of distress from POP compared with those in younger women regardless of the stage of prolapse (4). Pelvic organs are connected and are supported by the levator ani muscle complex, cardinal and uterosacral ligament (USL), endopelvic fascia and the pelvis itself (3). A connective tissue network forms the footing of the pelvic structures, where fibroblastic cells produce the extracellular matrix (ECM) proteins, including collagen I/III and fibronectin, which are necessary for sustaining the mechanical integrity of the normal pelvic structure (5). Any disruptions or malfunction in this cell-based support and suspension network will lead to the weakening of the pelvic floor, leading to prolapse $(6,7)$. In summary, the pathogenic mechanism of POP mainly results from the loss of anatomical support during aging.

On a cellular basis, general cell senescence is the predominant process driving aging. There are a number of phenotypes 
associated with cellular aging, including genomic instability, telomere attrition, epigenetic alterations, loss of proteostasis, dysregulated nutrient sensing, mitochondrial dysfunction, cellular senescence, stem cell exhaustion and altered intercellular communication (Fig. 1) (8). In the present review, the roles of cellular senescence in POP, in addition to the possible senescence biomarkers reported from previous POP studies, will be discussed. It is hoped that this information can provide novel insights into the pathogenesis of POP.

\section{Increases in oxidative stress causes fibroblast cell damage in the pelvic tissue}

Genetic alterations in resident cells in the pelvic tissues serve as the main hallmark of the aging process (8). The integrity and stability of DNA are constantly under threat from both exogenous and endogenous sources, including those provided by oxidative stress and enzymes associated with DNA, causing a variety of genetic lesions, including oxidative DNA replication errors, double-strand breaks and chromosome aberrations (9).

In terms of OS, reactive oxygen species (ROS) or OS levels are regulated by the balance between ROS production and elimination. Aging processes have been frequently associated with defective anti-oxidative systems. Kim et al (10) found that the levels of OS markers 8-hydroxy-2'-deoxyguanosine and 4-hydroxy-2-nonenal were increased in the USLs of patients with POP. OS activated a downstream effector of AKT, initiating the PI3K/AKT signaling pathway to promote fibroblast apoptosis in pelvic tissues and the reduction of type I collagen (11). A previous study reported that the antioxidant gene inducer nuclear factor erythroid-2-related factor 2 (Nrf2) counteracted ROS production. Mice deficient in Nrf 2 displayed higher stress urinary incontinence indices and increased levels of OS-induced apoptosis in vivo (12). In addition, higher levels of Nrf2 expression alleviated trauma-induced abnormalities in the anterior vaginal wall. Lower levels of Nrf2 and excessive OS induced the loss of fibroblasts and type I collagen in the pelvic tissue, which in turn weakened the force of pelvic supportive tissues (13).

Aside from aberrant redox signaling caused by senescence, endogenous ROS can also mediate DNA damage, revealing another mechanism associated with prolapse as a result of aging. The accumulation of oxidative products inhibits cell proliferation (14). Advanced glycation end products (AGEs) are products of non-enzymatic glycation and oxidation that frequently accumulate during aging. Several studies have previously revealed that AGEs inhibited human vaginal fibroblast proliferation in a number of POP cases, where they decreased the expression of collagen whilst increasing that of matrix metalloproteinase (MMP). These agents adjust the intracellular conditions by regulating the balance between MMPs and tissue inhibitors of metalloproteinases (TIMPs) in addition to gene expression (15). Following AGE treatment in vitro, increased expression of MMPs and reduced levels of TIMPs resulted in the rapid degradation of type I collagen and elastin, along with the subsequent loss of force in the supportive tissues (16). In senescent pelvic tissues, receptor of AGEs, p38 MAPK and NF- $\kappa \mathrm{B}$ signaling pathways partially mediated the effects of AGE treatment on fibroblasts from patients with POP by inhibiting collagen synthesis whilst upregulating
MMP-1 expression (17). Thus, the aforementioned studies suggested that the imbalanced senescent ROS/OS system may induce the accumulation of AGEs and suppress Nrf2 signaling, thereby inhibiting collagen/elastin synthesis through various molecular pathways.

\section{Mitochondrial dysfunction in fibroblasts}

Mitochondrial dysfunction and the decline in respiratory chain activity have been demonstrated to be a major characteristic of aging in numerous types of tissues, such as skin and nervous tissues (18). Dysfunctional mitochondria exhibit reduced respiratory capacity, imbalanced ROS levels, an increased number of mitochondrial DNA (mtDNA) mutations and altered mitochondrial biogenesis. mtDNA is highly sensitive to oxidative damage due to its proximity to the site of ROS production, and lack of standard chromatin structure or repair mechanism (19).

Mitochondrial fusion protein-2 (Mfn2) is a conserved dynamin-like GTPase protein localized to the mitochondrial outer membrane and regulates mitochondrial fusion (20). Mfn2 can also localize to the endoplasmic reticulum (ER) where it can mediate fusion between the mitochondria and $\operatorname{ER}(21,22)$. Previous studies demonstrated that the expression levels of Mfn2 were significantly higher in cultured fibroblasts from the elderly POP group, with reduced modulation of types I and III procollagen $(23,24)$. Concomitantly, cyclin-dependent kinase (CDK) 2, ERK1/2 and Raf-1 expression were also reduced, while that of the cell cycling signal phosphoprotein 21 wild-type p53 activating fragment (p21CIP1/WAF1) was adversely increased (23). Senescent cells in aging pelvic tissues represent a mitochondrial dysfunction. Via the Raf-ERK axis, cells such as mesenchymal stem cells suffer from rapid cell cycle arrest and functionally impaired fibroblasts secrete less extracellular matrix proteins, including collagen. In addition, dysfunctional mitochondria in the senescent fibroblasts of pelvic tissues overexpress Mfn2, resulting in the loss of procollagens via the Raf-ERK axis and rapid cell cycle arrest $(19,23)$.

\section{General cellular senescent phenotypes associated with the pathogenesis of $P O P$.}

Senescence is a cellular response which is characterized by stable growth arrest and phenotypic adjustments, such as the expression of proinflammatory factors (25-27). Molecules such as transforming growth factor- $\beta$ (TGF- $\beta$ ) are deactivated during fibroblast cell senescence in pelvic tissues (28). Senescent fibroblasts demonstrate distinctive mRNA expression profiles that involve a wide variety of cytokines, chemokines, proteases and growth factors (9).

When undergoing senescence, fibroblasts experience destruction in specific DNA sequences and genes, shortening of the telomere and the activation of the tumor suppressor p53. The $\mathrm{p} 53$ pathway upregulates $\mathrm{p} 21 \mathrm{CIP1/WAF1}$ signaling through the NF- $\kappa \mathrm{B}$ pathway. Meanwhile, senescence-mediated stimuli CDK4/6 activates the p16INK4A pathway, which operates in concert with $\mathrm{p} 21 \mathrm{CIP} 1 / \mathrm{WAF} 1$ in arresting cell cycle progression at the G1 phrase (29-31). Senescent fibroblasts accumulate in the pelvic tissue, where they exhaust the tissue of proliferative and renewable stem cells over time, interfering with the homeostatic and regenerative capacity of the pelvic tissues. With this 


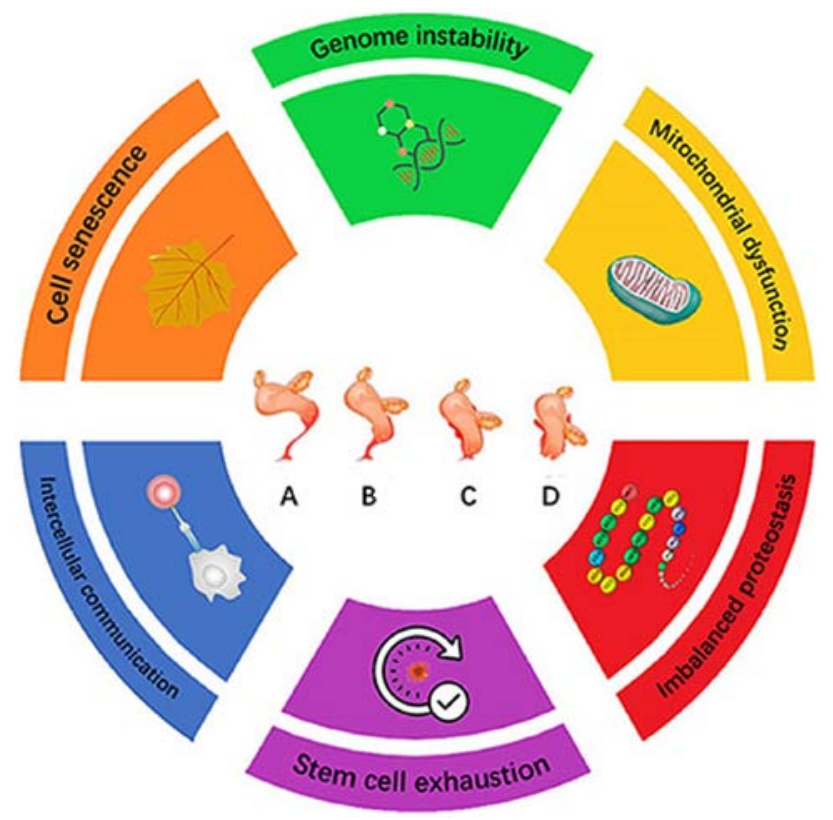

Figure 1. Hallmarks of the aging process for POP. The scheme presents the six hallmarks described in this review: Genomic instability, mitochondrial dysfunction, imbalanced proteostasis, cell senescence, intercellular communication and stem cell exhaustion. (A-D) Deterioration process of pelvic organ support according to the Pelvic Organ Prolapse Quantification system (78): Uterus and accessory organs in (A) the correct anatomical position, (B) patients with class I POP, (C) patients with class II POP and (D) patients with class III POP. POP, pelvic organ prolapse.

reduction in active fibroblasts, pelvic tissues are deprived of the collagen necessary to support the pelvic organs (28).

Procollagen types I and III are precursors to collagen I/III depending on the isoform of the active MMP. Senescent cells express reduced levels of TGF- $\beta$, which is an MMP regulator that suppresses the activity of MMP-2/9 $(28,32)$. USL collagen fibers constitute $80 \%$ of the connective tissues in the USL and are considered to be an essential component of the pelvic supporting structure (33). Loss of collagen I/III contributes to the weakened tensile force of the connective tissue. Specimens obtained from elderly patients with POP showed a significant reduction in TGF- $\beta 1$ expression compared with that in younger POP groups (34). As a result of the lower expression levels of TGF- $\beta$ associated with senescence in pelvic tissue fibroblasts, MMPs are activated to degrade collagen I/III in the pelvic supportive tissues. (Figs. 2 and 3).

Additionally, a previous study with other tissue dysfunctions such as prolapsus uteri previously demonstrated that the levels of the NF- $\mathrm{B}$ pathway-related p53 protein and mRNA are decreased in elderly prolapse groups, suggesting a higher proliferative capacity of prolapsus fibroblasts (35). Accompanied with the reduced expression of p53 and p21, an intrinsic perturbation of cell cycle progression occurs in the fibroblasts (36). The activation of senescent cell defensive system induces the loss of fibroblasts in pelvic tissues through apoptosis, necroptosis and autophagic cell death.

Previous studies with a number of senescence-associated secretory phenotypes suggested that cell senescence correlates strongly with the pathogenesis of POP $(11,16,23,28)$. In dermal fibroblasts, an in vivo experiment has confirmed the increased secretion of the cysteine-rich angiogenic inducer protein 61, also known as cellular communication network factor 1 (CCN1) (37). CCN1 is a matrix protein that stimulates the secretion of proinflammatory cytokines and MMPs. They also induce fibroblast senescence to limit tissue fibrosis during wound healing (38). A previous study also reported elevated CCN1 expression in elderly patients with POP, with a greater extent of fibroblast and collagen loss, suggesting that general fibroblast senescence results in the loss of structural support (Huang et al, unpublished data).

\section{Imbalanced proteostasis in fibroblasts of pelvic tissues}

Impaired protein synthesis and dysregulation of protein volume have demonstrated a close correlation with diseases associated with aging such as POP (39). Proteins are regulated by a sequenced mechanism to preserve stability and functionality, in a process known as proteostasis. Proteostasis encompasses mechanisms that preserve the stability of correctly folded proteins (40), where proteolytic systems remove damaged proteins (41-43). The unstable proteolytic systems during cellular senescence results in the decline of the proteasome (44).

Imbalanced proteostasis in elderly patients with POP presents as marked reductions in estrogen, leading to lower levels of mature enzymes, including the lysyl oxidase family of enzymes, a disintegrin and metalloproteinase with thrombospondin motifs and bone morphogenetic protein-1 (BMP1) $(45,46)$. Estrogen treatment on post-menopausal patients with POP resulted in the enhanced expression of collagens and elastin through regulation of the BMP1 and MMP/TIMP complexes to improve the wound healing process, in turn leading to the preservation of fibroblasts and supportive collagens (47). MMP-1, MMP-2 and MMP-3 showed a reduction in expression along with an increase in TIMP1/4 expression after estrogen treatment in elderly patients with POP (47). Observations from local estrogen therapy indicates the essential role of proteostasis during senescence within the pelvic tissue environment, including the balance 


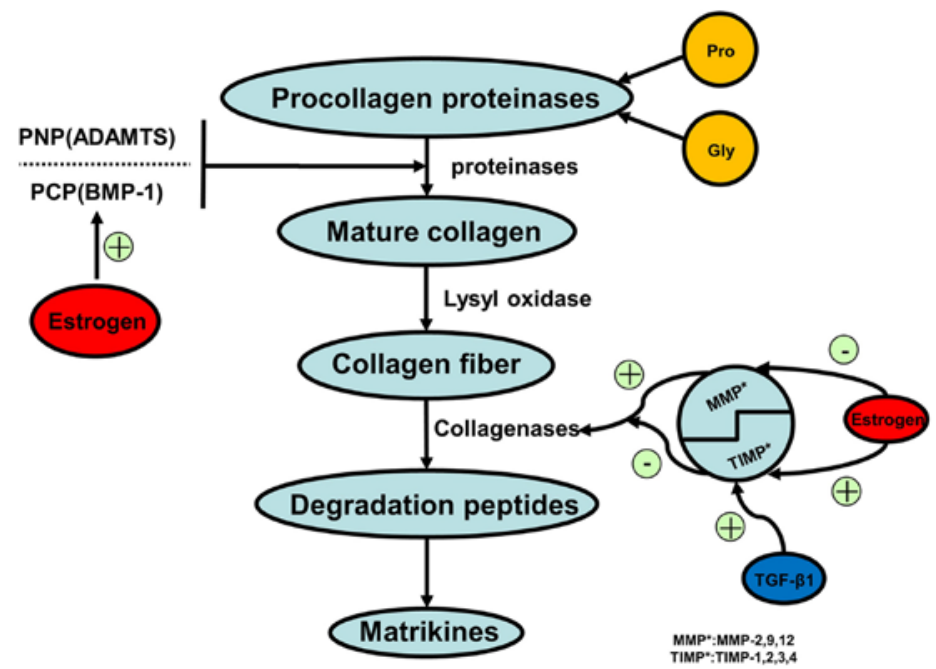

Figure 2. Collagen synthesis. Synthesis of collagen in human cells, such as myofibroblasts, fibroblasts, cardiomyocytes and inflammatory cells. Amino acids synthesize the procollagen that transforms to mature collagen via proteinase activity. Lysyl oxidase continuously catalyzes to form collagen fibers. During degradation, collagenases break down collagen fibers to peptides and matrikines. The lysyl oxidase family, and BMP-1-ADAMTS and MMP-TIMP complexes play an essential role in mature collagen synthesis and collagen fiber degradation processes. MMP, matrix metalloprotein; TIMP, tissue inhibitor of metalloproteinase; BMP-1, bone morphogenetic protein-1; ADAMTS, a disintegrin and metalloproteinase with thrombospondin motifs; TGF- $\beta$, transforming growth factor $\beta$.

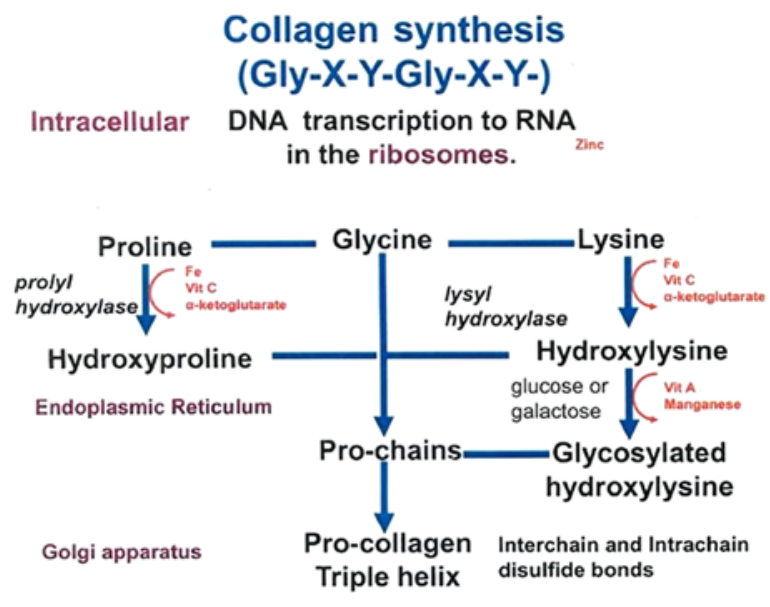

Extracellular $\quad \begin{aligned} & \text { Cleavage of amino and carboxyl } \\ & \text { terminal pro-peptides }\end{aligned}$

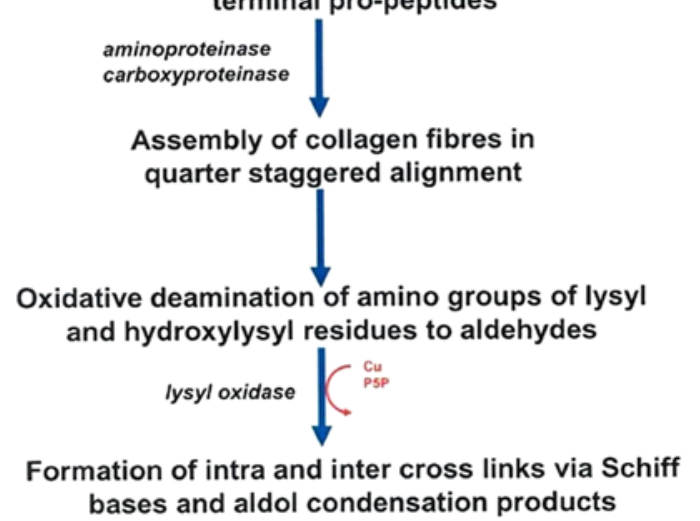

Figure 3. Location and process of collagen assembly. Underlying intracellular pathways, proline, glycine and lysine synthesize procollagen triple helix via proteinase activity. Underlying extracellular pathways, procollagen fibers are modified and tightened to form effective and functional collagens catalyzed by carboxyproteinase and lysyl oxidase.

between BMP1, MMP/TIMP and procollagen/collagen. In this regard, estrogen serves to balance the protein levels, limit undesirable ECM degradation and to strengthen the vaginal ECM supporting structures. 
Table I. Evidence of the possible genes or biomarkers in patients with POP, compared with normal dermal fibroblast.

\begin{tabular}{|c|c|c|c|}
\hline Types of aging & $\begin{array}{l}\text { Evidence in vitro } \\
\text { culture }\end{array}$ & $\begin{array}{c}\text { Evidence ex vivo } \\
\text { from patients with } \\
\text { POP }\end{array}$ & $\begin{array}{c}\text { Evidence in vivo from the } \\
\text { dermal fibroblasts in } \\
\text { the elderly }\end{array}$ \\
\hline \multicolumn{4}{|l|}{ Genome instability } \\
\hline $\begin{array}{l}\text { HOXA11, } \\
\text { HOXA13, ESR } 1 \text { and } \\
\text { ESR2 }\end{array}$ & Y (49) & $Y(62)$ & ND \\
\hline$\gamma \mathrm{H} 2 \mathrm{AX}$ foci & $\mathrm{Y}(50)$ & $\mathrm{Y}(17)$ & $Y(16)$ \\
\hline Mutant NER & Y (59) & ND & ND \\
\hline Replicative activity & $Y(60)$ & ND & ND \\
\hline Telomere shortening & $Y(61,62)$ & $Y(63)$ & ND \\
\hline Telomere damage & $\mathrm{Y}(50)$ & ND & Y (16) \\
\hline \multicolumn{4}{|l|}{ Mitochondrial dysfunction } \\
\hline mtDNA mutations & $\mathrm{Y}(64,65)$ & ND & ND \\
\hline Altered fusion & ND & Y (67) & ND \\
\hline Increasing mitogenesis & $Y(69,70)$ & ND & \\
\hline \multicolumn{4}{|l|}{ Cell senescence } \\
\hline $\mathrm{p} 16^{\mathrm{INK} 4 \mathrm{~A}}$ & $\mathrm{Y}(71)$ & ND & $Y(66,67)$ \\
\hline $\mathrm{p} 21$ & $\mathrm{Y}(72,73)$ & $\mathrm{Y}(78)$ & ND \\
\hline p53 & ND & Y (78) & ND \\
\hline SASP & Y (74) & Y (74) & ND \\
\hline SAHF & $\mathrm{Y}(75,76)$ & ND & Y (68) \\
\hline$\gamma \mathrm{H} 2 \mathrm{AX}$ foci & $\mathrm{Y}(50)$ & ND & Y (16) \\
\hline \multicolumn{4}{|l|}{ Imbalanced proteostasis } \\
\hline Chaperon dysfunction & ND & Y (78) & ND \\
\hline Proteasome activity & $Y(42,77)$ & ND & ND \\
\hline Decreased autophagy & ND & ND & ND \\
\hline Increased MMP secretion & $\mathrm{Y}(43)$ & Y (39) & Y (39) \\
\hline \multicolumn{4}{|l|}{ Stem cell exhaustion } \\
\hline Regeneration potential & ND & ND & ND \\
\hline
\end{tabular}

HOXA11, homeobox A11; HOXA13, homeobox A13; Y, evidence confirmed; ND, no data; ESR1, estrogen receptor 1; ESR2, estrogen receptor 2; $\gamma \mathrm{H} 2 \mathrm{AX}, \mathrm{H} 2 \mathrm{AX}$ histone protein phosphorylated at the serine-139 position; NER, nucleotide excision repair; SASP, senescence-associated secretory phenotype; SAHF, senescence-associated heterochromatin aggregation; MMP, matrix metalloprotein; mtDNA, mitochondrial DNA.

Muscle dysfunction is also one of the causes of organ prolapse in the pelvis (6). In a similar manner, heat-shock protein 72 (hsp72) induced the intrinsic preservation of muscle function and postponed the development of dystrophic muscle changes. Hsp72 is highly expressed in patients with POP together with other molecules, where they ensure the correct folding of newly generated proteins, especially collagen and actin, in addition to the refolding of damaged proteins to maintain the force of pelvic tissues (48). Dysfunctional proteins accumulate in muscle cells as the Hsp family of proteins, autophagy-lysosome and ubiquitin-proteasome systems decline with aging, resulting in muscle dysfunction (49).

\section{Obstacles and outlook}

The present review presented some findings on the underlying mechanism of fibroblast senescence on the pathogenesis of
POP. Thus far, available interventions for patients with POP include surgical, non-surgical and physical interventions, which are mainly focused on the physical conditions of the supportive structures, where the ligaments are overhung or the introitus is sealed (50). These interventions may gradually lead to either palindromia or other adverse effects such as postoperative dysuria and urethral injury long term (50). Therapies that focus on reversing the senescent process solve the issue from the root and will not do harm to the important structures in the pelvis. The mechanism of POP pathogenesis requires further research in patients. In the present article, novel assessments on drug therapy, biomaterial supplement and stem cell treatment on POP are proposed. Estrogen serves a protective role in maintaining the pelvic tissue microenvironment in women, where the mechanism of estrogen affecting the synthesis of fibroblast is as aforementioned. Estrogen shock therapy can be used as 
an effective therapeutic option for POP. In a similar manner, in the biomaterial assessment on patients with POP, TGF- $\beta$ can be used in addition to the partially absorbable material donut pessaries, using the newly proposed biomaterial caffeic acid conjugated with peptide as an alternative to reduce the process of senescence, whilst adjusting the microenvironment in pelvic tissues (51).

During the process of aging, several types of stem cells lose their quiescence, leading to excessive proliferation and their regenerative potential (52). Notable examples include age-related hematopoietic stem cell-induced anemia and the aging mesenchymal stem cell (MSC)-induced reduction in fracture repair (8). In terms of stem cell therapy, MSCs show a multi-directive differentiation ability, whose loss of regenerative capacity lead to the impaired ability to facilitate tissue repair, thereby increasing morbidity (53). In terms of aging, taking advantage of the differentiation ability of bone marrow-derived MSCs and their secretory factors, which are beneficial for tissue repair and elastin regeneration $(54,55)$ is now being considered as another alternative for vaginal prolapse to reactivate the stem cells (56). MSCs are not only able to transdifferentiate into various cell types present in the pelvic tissues and maintain collagen secretion with neovascularization but they can also deliver bioactive molecules to sites of injury to promote fibroblast proliferation and collagen synthesis (57). Although there remains a lack of sufficient studies on the possibility of senescent therapy in POP, a recent review shed light on a potential stem cell therapy strategy. The stem cells can be combined with mesh, which can be inserted into the bladder neck for POP treatment by inducing vascular endothelial growth factor, platelet-derived growth factor- $\beta$ and TGF- $\beta$, which have been reported to delay the senescence process and improve tissue repairs (51).

\section{Conclusion}

Knowledge on the pathogenesis of POP remains multifactorial, which can be mainly attributed to the general aging of the individual and overall senescence of the fibroblasts in pelvic tissues. This causes the exhaustion or apoptosis of the fibroblasts in the pelvic floor, reducing its supportive ability and integrity. The main five hallmarks of POP associated with aging were reviewed primarily based on a previous review on the hallmarks of general aging. Genomic instability and imbalanced proteostasis are likely to be the primary triggers of aging-related prolapse. Mitochondrial dysfunction in the progression of senescence may consequentially become the integrated cause of POP. Cell senescence, one facet of the aging process, is a collective phenotype caused by a complex network of signaling pathways. Mechanisms causing fibroblast senescence, including gene instability, mitochondrial dysfunction and altered senescence-symbolized phenotype, provide a basis for senescence-related POP pathological mechanisms (Table I) $(16,17,39,42,43,49,50,58-77)$. Nevertheless, with an improved understanding of the effect of senescence on POP, currently available clinical treatments could potentially be applied in conjunction with estrogen treatment and stem cell-based material with the aim of reversing fibroblast senescence in patients with POP in the future.

\section{Acknowledgements}

Not applicable.

\section{Funding}

The present study was supported by The Foundation of Sichuan Provincial Science and Technology Program (grant nos. 2019YFH0147 and 2019YFH0158), Chengdu technological innovation research and development project (grant no. 2018-YF05-00195-SN), West China Second University Hospital Xinya fund (grant no. kx111) and 1.3.5 project for disciplines of excellence, West China Hospital, Sichuan University (grant no. ZYJC18016).

\section{Availability of data and materials}

The datasets generated and/or analyzed during the current study are available in the NCBI repository, https://www.ncbi. nlm.nih.gov.

\section{Authors' contributions}

$\mathrm{LH}, \mathrm{ZZ}$ and JW conceived and designed the review, tables and figures, and drafted the manuscript. YM, JW and WL researched the literature and critically revised the article for important intellectual content. All authors read and approved the final manuscript.

\section{Ethics approval and consent to participate}

Not applicable.

\section{Patient consent for publication}

Not applicable.

\section{Competing interests}

The authors declare that they have no competing interests.

\section{References}

1. Iglesia CB and Smithling KR: Pelvic organ prolapse. Am Fam Physician 96: 179-185, 2017.

2. Nygaard I, Barber MD, Burgio KL, Kenton K, Meikle S, Schaffer J, Spino C, Whitehead WE, Wu J and Brody DJ; Pelvic floor disorders network: Prevalence of symptomatic pelvic floor disorders in US women. JAMA 300: 1311-1316, 2008.

3. Jelovsek JE, Maher C and Barber MD: Pelvic organ prolapse. Lancet 369: 1027-1038, 2007.

4. Kinman CL, Lemieux CA, Agrawal A, Gaskins JT, Meriwether KV and Francis SL: The relationship between age and pelvic organ prolapse bother. Int Urogynecol J Pelvic Floor Dysfunct 28: 751-755, 2017.

5. Sun B, Zhou L, Wen Y, Wang C, Baer TM, Pera RR and Chen B: Proliferative behavior of vaginal fibroblasts from women with pelvic organ prolapse. Eur J Obstet Gynecol Reprod Biol 183: $1-4,2014$.

6. Richardson AC, Lyon JB and Williams NL: A new look at pelvic relaxation. Am J Obstet Gynecol 126: 568-573, 1976.

7. Jackson SR, Avery NC, Tarlton JF, Eckford SD, Abrams P and Bailey AJ: Changes in metabolism of collagen in genitourinary prolapse. Lancet 347: 1658-1661, 1996.

8. López-Otín C, Blasco MA, Partridge L, Serrano M and Kroemer G: The hallmarks of aging. Cell 153: 1194-1217, 2013. 
9. Tigges J, Krutmann J, Fritsche E, Haendeler J, Schaal H, Fischer JW, Kalfalah F, Reinke H, Reifenberger G, Stühler K, et al: The hallmarks of fibroblast ageing. Mech Ageing Dev 138: 26-44, 2014

10. Kim EJ, Chung N, Park SH, Lee KH, Kim SW, Kim JY, Bai SW and Jeon MJ: Involvement of oxidative stress and mitochondrial apoptosis in the pathogenesis of pelvic organ prolapse. J Urol 189: 588-594, 2013.

11. Li BS, Guo WJ, Hong L, Liu YD, Liu C, Hong SS, Wu DB and Min J: Role of mechanical strain-activated PI3K/Akt signaling pathway in pelvic organ prolapse. Mol Med Rep 14: 243-253, 2016.

12. Tian X, Wang F, Luo Y, Ma S, Zhang N, Sun Y, You C, Tang G, Li S, Gong Y, et al: Protective role of nuclear factor-erythroid 2-related factor 2 against radiation-induced lung injury and inflammation. Front Oncol 8: 542, 2018.

13. Yang W, Sun Z, Yang B and Wang Q: Nrf2-knockout protects from intestinal injuries in C57BL/6J mice following abdominal irradiation with $\gamma$ rays. Int J Mol Sci 18: E1656, 2017.

14. Møller P, Løhr M, Folkmann JK, Mikkelsen L and Loft S: Aging and oxidatively damaged nuclear DNA in animal organs. Free Radic Biol Med 48: 1275-1285, 2010.

15. Gkogkolou P and Böhm M: Advanced glycation end products: key players in skin aging? Dermatoendocrinol 4: 259-270, 2012.

16. Willett TL, Pasquale J and Grynpas MD: Collagen modifications in postmenopausal osteoporosis: Advanced glycation end products may affect bone volume, structure and quality. Curr Osteoporos Rep 12: 329-337, 2014.

17. Chen YS, Wang XJ, Feng W and Hua KQ: Advanced glycation end products decrease collagen I levels in fibroblasts from the vaginal wall of patients with POP via the RAGE, MAPK and NF- $\kappa$ B pathways. Int J Mol Med 40: 987-998, 2017.

18. Nunnari J and Suomalainen A: Mitochondria: In sickness and in health. Cell 148: 1145-1159, 2012.

19. Kim SJ, Cheresh P, Jablonski RP, Williams DB and Kamp DW: The role of mitochondrial DNA in mediating alveolar epithelial cell apoptosis and pulmonary fibrosis. Int $\mathrm{J}$ Mol Sci 16 : 21486-21519, 2015

20. Chen H, Detmer SA, Ewald AJ, Griffin EE, Fraser SE and Chan DC: Mitofusins Mfn1 and Mfn2 coordinately regulate mitochondrial fusion and are essential for embryonic development. J Cell Biol 160: 189-200, 2003

21. de Brito OM and Scorrano L: Mitofusin 2 tethers endoplasmic reticulum to mitochondria. Nature 456: 605-610, 2008.

22. Sebastián D, Hernández-Alvarez MI, Segalés J, Sorianello E, Muñoz JP, Sala D, Waget A, Liesa M, Paz JC, Gopalacharyulu P, et al: Mitofusin 2 (Mfn2) links mitochondrial and endoplasmic reticulum function with insulin signaling and is essential for normal glucose homeostasis. Proc Natl Acad Sci USA 109: 5523-5528, 2012

23. Wang X, Wang X, Zhou Y, Peng C, Chen H and Lu Y: Mitofusin2 regulates the proliferation and function of fibroblasts: The possible mechanisms underlying pelvic organ prolapse development. Mol Med Rep 20: 2859-2866, 2019

24. Lu Y, Chen HY, Wang XQ and Wang JX: Correlations between Mitofusin 2 expression in fibroblasts and pelvic organ prolapse: An in vitro study. Chin Med J (Engl) 130: 2951-2959, 2017.

25. McHugh D and Gil J: Senescence and aging: Causes, consequences, and therapeutic avenues. J Cell Biol 217: 65-77, 2018.

26. Burton DG and Krizhanovsky V: Physiological and pathological consequences of cellular senescence. Cell Mol Life Sci 71: 4373-4386, 2014

27. Kirkland JL and Tchkonia T: Cellular senescence: A translational perspective. EBioMedicine 21: 21-28, 2017.

28. Chen B and Yeh J: Alterations in connective tissue metabolism in stress incontinence and prolapse. J Urol 186: 1768-1772, 2011.

29. Alcorta DA, Xiong Y, Phelps D, Hannon G, Beach D and Barrett JC: Involvement of the cyclin-dependent kinase inhibitor p16 (INK4a) in replicative senescence of normal human fibroblasts. Proc Natl Acad Sci USA 93: 13742-13747, 1996.

30. Takahashi A, Ohtani N, Yamakoshi K, Iida S, Tahara H, Nakayama K, Nakayama KI, Ide T, Saya H and Hara E: Mitogenic signalling and the p16INK4a-Rb pathway cooperate to enforce irreversible cellular senescence. Nat Cell Biol 8 : 1291-1297, 2006

31. Beauséjour CM, Krtolica A, Galimi F, Narita M, Lowe SW, Yaswen P and Campisi J: Reversal of human cellular senescence: Roles of the p53 and p16 pathways. EMBO J 22: 4212-4222, 2003 .
32. Sampson N, Berger P and Zenzmaier C: Redox signaling as a therapeutic target to inhibit myofibroblast activation in degenerative fibrotic disease. BioMed Res Int 2014: 131737, 2014

33. Cole EE, Leu PB, Gomelsky A, Revelo P, Shappell H, Scarpero HM and Dmochowski RR: Histopathological evaluation of the uterosacral ligament: Is this a dependable structure for pelvic reconstruction? BJU Int 97: 345-348, 2006.

34. Liu C, Wang Y, Li BS, Yang Q, Tang JM, Min J, Hong SS, Guo WJ and Hong L: Role of transforming growth factor $\beta 1$ in the pathogenesis of pelvic organ prolapse: A potential therapeutic target. Int J Mol Med 40: 347-356, 2017.

35. Yamamoto $\mathrm{K}$, Yamamoto $\mathrm{M}$, Akazawa $\mathrm{K}$, Tajima $\mathrm{S}$, Wakimoto $\mathrm{H}$ and Aoyagi $\mathrm{M}$ : Decrease in elastin gene expression and protein synthesis in fibroblasts derived from cardinal ligaments of patients with prolapsus uteri. Cell Biol Int 21: 605-611, 1997.

36. Yamamoto $M$, Aoyagi $M$, Akazawa $K$, Tajima $S$ and Yamamoto K: Decrease in p53 protein in cultured cardinal ligament fibroblasts from patients with prolapsus uteri. Cell Biol Int 22: 31-40, 1998.

37. Quan T, Qin Z, Robichaud P, Voorhees JJ and Fisher GJ: CCN1 contributes to skin connective tissue aging by inducing age-associated secretory phenotype in human skin dermal fibroblasts. J Cell Commun Signal 5: 201-207, 2011.

38. Jun JI and Lau LF: The matricellular protein CCN1 induces fibroblast senescence and restricts fibrosis in cutaneous wound healing. Nat Cell Biol 12: 676-685, 2010.

39. Powers ET, Morimoto RI, Dillin A, Kelly JW and Balch WE: Biological and chemical approaches to diseases of proteostasis deficiency. Annu Rev Biochem 78: 959-991, 2009.

40. Hartl FU, Bracher A and Hayer-Hartl M: Molecular chaperones in protein folding and proteostasis. Nature 475: 324-332, 2011.

41. Brennan M, Bhatti H, Nerusu KC, Bhagavathula N, Kang S, Fisher GJ, Varani J and Voorhees JJ: Matrix metalloproteinase-1 is the major collagenolytic enzyme responsible for collagen damage in UV-irradiated human skin. Photochem Photobiol 78: 43-48, 2003.

42. Cuervo AM, Bergamini E, Brunk UT, Dröge W, Ffrench M and Terman A: Autophagy and aging: The importance of maintaining 'clean' cells. Autophagy 1: 131-140, 2005.

43. Mizushima N, Levine B, Cuervo AM and Klionsky DJ: Autophagy fights disease through cellular self-digestion. Nature 451: 1069-1075, 2008

44. Bulteau AL, Moreau M, Nizard C and Friguet B: Proteasome and photoaging: The effects of UV irradiation. Ann N Y Acad Sci 1100: 280-290, 2007.

45. Pereira L, D'Alessio M, Ramirez F, Lynch JR, Sykes B, Pangilinan $\mathrm{T}$ and Bonadio $\mathrm{J}$ : Genomic organization of the sequence coding for fibrillin, the defective gene product in Marfan syndrome. Hum Mol Genet 2: 1762, 1993.

46. Zhang H, Hu W and Ramirez F: Developmental expression of fibrillin genes suggests heterogeneity of extracellular microfibrils. J Cell Biol 129: 1165-1176, 1995.

47. Tyagi T, Alarab M, Leong Y, Lye S and Shynlova O: Local oestrogen therapy modulates extracellular matrix and immune response in the vaginal tissue of post-menopausal women with severe pelvic organ prolapse. J Cell Mol Med 23: 2907-2919, 2019.

48. Calamini B and Morimoto RI: Protein homeostasis as a therapeutic target for diseases of protein conformation. Curr Top Med Chem 12: 2623-2640,2012.

49. Tomaru U, Takahashi S, Ishizu A, Miyatake Y, Gohda A, Suzuki S, Ono A, Ohara J, Baba T, Murata S, et al: Decreased proteasomal activity causes age-related phenotypes and promotes the development of metabolic abnormalities. Am J Pathol 180: 963-972, 2012

50. Coolen AWM, Troost S, Mol BWJ, Roovers JPWR and Bongers MY: Primary treatment of pelvic organ prolapse: Pessary use versus prolapse surgery. Int Urogynecol J Pelvic Floor Dysfunct 29: 99-107, 2018.

51. Cheng J, Zhao ZW, Wen JR, Wang L, Huang LW, Yang YL, Zhao FN, Xiao JY, Fang F, Wu J, et al: Status, challenges, and future prospects of stem cell therapy in pelvic floor disorders. World J Clin Cases 8: 1400-1413, 2020.

52. Shaw AC, Joshi S, Greenwood H, Panda A and Lord JM: Aging of the innate immune system. Curr Opin Immunol 22: 507-513, 2010.

53. Kirkwood TB: Understanding the odd science of aging. Cell 120: 437-447, 2005 
54. Jin $\mathrm{M}$, Wu Y, Wang J, Ye W, Wang L, Yin P, Liu W, Pan C and Hua X: MicroRNA-29 facilitates transplantation of bone marrow-derived mesenchymal stem cells to alleviate pelvic floor dysfunction by repressing elastin. Stem Cell Res Ther 7: 167, 2016.

55. Jin M, Chen Y, Zhou Y, Mei Y, Liu W, Pan C and Hua X: Transplantation of bone marrow-derived mesenchymal stem cells expressing elastin alleviates pelvic floor dysfunction. Stem Cell Res Ther 7: 51, 2016

56. Ulrich D, Edwards SL, Su K, Tan KS, White JF, Ramshaw JA, Lo C, Rosamilia A, Werkmeister JA and Gargett CE: Human endometrial mesenchymal stem cells modulate the tissue response and mechanical behavior of polyamide mesh implants for pelvic organ prolapse repair. Tissue Eng Part A 20: 785-798, 2014.

57. El Agha E, Kramann R, Schneider RK, Li X, Seeger W, Humphreys BD and Bellusci S: Mesenchymal stem cells in fibrotic disease. Cell Stem Cell 21: 166-177, 2017.

58. Ohshima S: Centrosome aberrations associated with cellular senescence and p53 localization at supernumerary centrosomes. Oxid Med Cell Longev 2012: 217594, 2012.

59. Fumagalli M, Rossiello F, Clerici M, Barozzi S, Cittaro D Kaplunov JM, Bucci G, Dobreva M, Matti V,Beausejour CM, et al: Telomeric DNA damage is irreparable and causes persistent DNA-damage-response activation. Nat Cell Biol 14: 355-365, 2012.

60. Garm C, Moreno-Villanueva M, Bürkle A, Petersen I, Bohr VA, Christensen K and Stevnsner T: Age and gender effects on DNA strand break repair in peripheral blood mononuclear cells. Aging Cell 12: 58-66, 2013.

61. De Cecco M, Criscione SW, Peckham EJ, Hillenmeyer S, Hamm EA, Manivannan J, Peterson AL, Kreiling JA, Neretti N and Sedivy JM: Genomes of replicatively senescent cells undergo global epigenetic changes leading to gene silencing and activation of transposable elements. Aging Cell 12: 247-256, 2013

62. Harley CB, Futcher AB and Greider CW: Telomeres shorten during ageing of human fibroblasts. Nature 345: 458-460, 1990.

63. Sedelnikova OA, Horikawa I, Zimonjic DB, Popescu NC, Bonner WM and Barrett JC: Senescing human cells and ageing mice accumulate DNA lesions with unrepairable double-strand breaks. Nat Cell Biol 6: 168-170, 2004.

64. Hoeijmakers JH: DNA damage, aging, and cancer. N Engl J Med 361: 1475-1485, 2009.

65. Herbig U, Ferreira M, Condel L, Carey D and Sedivy JM Cellular senescence in aging primates. Science 311: 1257, 2006.

66. Krutmann J and Schroeder P: Role of mitochondria in photoaging of human skin: The defective powerhouse model. J Investig Dermatol Symp Proc 14: 44-49, 2009.
67. Ressler S, Bartkova J, Niederegger H, Bartek J Scharffetter-Kochanek K, Jansen-Dürr P and Wlaschek M: p16INK4A is a robust in vivo biomarker of cellular aging in human skin. Aging Cell 5: 379-389, 2006.

68. Jeyapalan JC, Ferreira M, Sedivy JM and Herbig U: Accumulation of senescent cells in mitotic tissue of aging primates. Mech Ageing Dev 128: 36-44, 2007.

69. Kreiling JA, Tamamori-Adachi M, Sexton AN, Jeyapalan JC, Munoz-Najar U, Peterson AL, Manivannan J, Rogers ES, Pchelintsev NA, Adams PD, et al: Age-associated increase in heterochromatic marks in murine and primate tissues. Aging Cell 10: 292-304, 2011.

70. Hayflick L: The biology of human aging. Adv Pathobiol 7: 80-99, 1980.

71. Lee HC, Yin PH, Chi CW and Wei YH: Increase in mitochondrial mass in human fibroblasts under oxidative stress and during replicative cell senescence. J Biomed Sci 9: 517-526, 2002.

72. d'Adda di Fagagna F, Reaper PM, Clay-Farrace L, Fiegler H, Carr P, Von Zglinicki T, Saretzki G, Carter NP and Jackson SP: A DNA damage checkpoint response in telomere-initiated senescence. Nature 426: 194-198, 2003.

73. Passos JF, Nelson G, Wang C, Richter T, Simillion C, Proctor CJ, Miwa S, Olijslagers S, Hallinan J, Wipat A, et al: Feedback between $\mathrm{p} 21$ and reactive oxygen production is necessary for cell senescence. Mol Syst Biol 6: 347, 2010.

74. Herbig U, Jobling WA, Chen BP, Chen DJ and Sedivy JM: Telomere shortening triggers senescence of human cells through a pathway involving ATM, p53, and p21(CIP1), but not p16(INK4a). Mol Cell 14: 501-513, 2004.

75. Coppé JP, Desprez PY, Krtolica A and Campisi J: The senescence-associated secretory phenotype: The dark side of tumor suppression. Annu Rev Pathol 5: 99-118, 2010.

76. Narita M, Nũnez S, Heard E, Narita M, Lin AW, Hearn SA, Spector DL, Hannon GJ and Lowe SW: Rb-mediated heterochromatin formation and silencing of E2F target genes during cellular senescence. Cell 113: 703-716, 2003.

77. Gabriel B, Denschlag D, Göbel H, Fittkow C, Werner M, Gitsch G and Watermann D: Uterosacral ligament in postmenopausal women with or without pelvic organ prolapse. Int Urogynecol J Pelvic Floor Dysfunct 16: 475-479, 2005.

78. Bump RC, Mattiasson A, Bø K, Brubaker LP, DeLancey JO, Klarskov P, Shull BL and Smith AR: The standardization of terminology of female pelvic organ prolapse and pelvic floor dysfunction. Am J Obstet Gynecol 175: 10-17, 1996.

This work is licensed under a Creative Commons Attribution-NonCommercial-NoDerivatives 4.0 International (CC BY-NC-ND 4.0) License. 